\title{
Satellite orbit determination by transfer with differenced ranges
}

\author{
YANG Ying $^{1,2,3^{*}}$, LI ZhiGang ${ }^{1,2}$, YANG XuHai ${ }^{1,2}$, FENG ChuGang $^{4} \&$ CAO Fen ${ }^{1,2,3}$ \\ ${ }^{1}$ National Time Service Center, Chinese Academy of Sciences, Xi'an 710600, China; \\ ${ }^{2}$ Key Laboratory for Precise Navigation, Positioning and Timing of the Chinese Academy of Sciences, Xi'an 710600, China; \\ ${ }^{3}$ Graduate University of Chinese Academy of Sciences, Beijing 100049, China; \\ ${ }^{4}$ Shanghai Astronomical Observatory, Chinese Academy of Sciences, Shanghai 200030, China
}

Received June 1, 2012; accepted August 9, 2012

\begin{abstract}
The original idea of orbit determination called "determination of satellite orbit by transfer" was proposed by the National Time Service Center, Chinese Academy of Sciences. It shows that the system is very stable and the orbit determination accuracy is improved greatly. A new observation mode called "differenced ranges between master station and slave stations by transfer" is introduced. It is the development of "determination of satellite orbit by transfer". In principle, the differenced ranges between master station and slave stations have a high angular resolution, and strongly constrains in the transverse direction of satellite orbit, perpendicular to the line-of-sight. The principle of "differenced ranges between master station and slave stations by transfer" is discussed in detail. And differenced ranges in combination with ranging data were used to determine satellite's orbit and orbit prediction under different arc observations. It shows that orbit determination accuracy for orbit prediction can be improved with differenced ranges in combination with ranging data.
\end{abstract}

transfer, differenced ranges, precise orbit determination (POD), orbit prediction

Citation: Yang Y, Li Z G, Yang X H, et al. Satellite orbit determination by transfer with differenced ranges. Chin Sci Bull, 2012, 57: 4701-4706, doi: $10.1007 / \mathrm{s} 11434-012-5507-2$

The developing Chinese area positioning system (CAPS) is a regional satellite navigation system. Its space segment consists of some geostationary earth orbit (GEO) satellites and 2-3 inclined geosynchronous orbit (IGSO) satellites $[1,2]$. The orbit determination of GEO satellites and IGSO satellites with high precision and accuracy is a key to construct such a satellite positioning system.

As a conventional satellite tracking technique, united S-band ranging (USB) system generally attains orbit determination accuracy of hundred-meter-level with ranging biases of 3-5 m. But a meter-level accuracy of precise orbit determination (POD) is required for the navigation system. The orbital period of the GEO matches the period of the Earth's rotation, so the relative motion of GEO satellites to the ground is smaller. The usual techniques of orbit determination are not able to obtain the precise orbit of the GEO satellites. Although the ranging accuracy for laser ranging

*Corresponding author (email: xiyinghe6@163.com) satellite (LRS) is very high, about $1 \mathrm{~cm}$, but the observations are limited by a weather condition, if the ranging stations are in the area of China, and the coverage of observation for the GEO is limited. It is not suitable for regular observations of orbit determination of GEO satellites $[3,4]$. Obviously, it is demanded to develop a new kind of tracking techniques.

The two-way satellite time and frequency transfer (TWSTFT) is a technique of time transfer with high accuracy. Based on high accuracy of TWSTFT technique, an original method for accuracy and precise determination of pseudo range, called "orbit determination by transfer" was proposed by the National Time Service Center, the Chinese Academy of Sciences [3]. The principle for "determination of satellite orbit by transfer" is that precise time signals from atomic clocks of ground stations modeled with different pseudo-noise code sequence are disseminated with the same carrier frequencies. The time signals are transferred via satellite transponder and received by receivers at some 
stations, in such a way, that the time delay on the propagation path can be determined. It means that the distances between satellite and stations via satellite are determined. The ranging signals are generated and measured at ground. There are auto-correction systems to determinate instrumentation time delay at stations in the real time. Therefore, such a system is very stable and the observation accuracy is improved greatly [3]. The different modes are constructed by combinations of received signals from different stations. Receivers at stations receive their own station disseminated signals, and it is called "receiving own station disseminated signals mode". Receivers at stations only receive the signals from the master station, and it is called "receiving master station disseminated signals mode". The accuracy and precision for both of modes are nearly the same, the ranging accuracy is better than $1 \mathrm{~cm}$, and $9 \mathrm{~cm}$ for the residuals of orbit determination. The precision of orbit determination is better than $2 \mathrm{~m}$ [3]. The observation modes discussed above provide a stronger constraint in the line-of-sight direction only.

A new observation mode named differenced ranges mode for determination of satellite orbit by transfer is introduced. The principle of this observation mode is the same as very long baseline interferometry (VLBI), it is able to strongly constrain in the transverse directions of the satellite orbit, perpendicular to the line-of-sight. In this paper, the principle of "differenced ranges between master station and slave stations" is discussed, and the analysis of satellite orbit determination and orbit prediction used differenced ranges in combination with ranging data is also made.

\section{Principle of differenced ranges between master station and slave stations by transfer}

The mode of differenced ranges between master station and slave stations is a new observation mode for determination of satellite orbit by transfer. The time signals from master station via satellite transponder are transmitted to receivers at ground stations (master station and slave stations), and the receivers at master station and slave stations received the signals from master station via satellite transponder simultaneously, in such a way, the distances between master station and slave stations via satellite are determined. Various differenced data can be obtained from making the difference of the ranges between master station to master station and master station to each slave station via satellite transponder. Obviously, the principle of this observation is the same as VLBI [5-7]. Figure 1 shows the principle of differenced ranges between master station and slave stations by transfer. There are 4 baselines of differenced ranges between master station and slave stations, the baseline between Lintong and Shanghai is $1177451.2031 \mathrm{~m}$, between Lintong and Changchun is $1739871.8266 \mathrm{~m}$, between Lintong and Kunming is $1205333.5743 \mathrm{~m}$, and between Lintong and Urumqi is $2142480.4966 \mathrm{~m}$. The precision of baselines

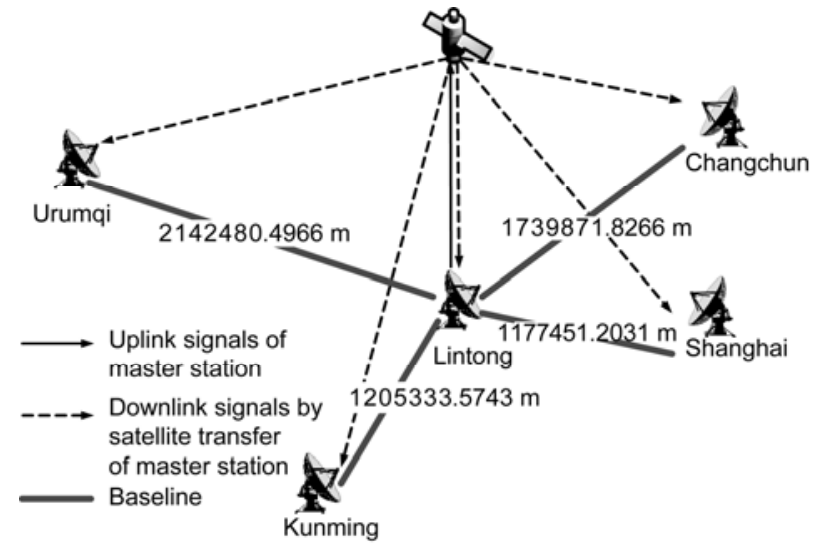

Figure 1 Principle of differenced ranges between master station and slave stations by transfer.

depends on the precision of coordinate of the stations; the precision of coordinate of the stations is $5 \mathrm{~mm}$, while the corresponding precision of baselines is better than $1 \mathrm{~cm}$.

Corrected the impact of ionosphere and troposphere, ionosphere correction adopt the prediction model which proposed by $\mathrm{Li}$ et al. [8] and troposphere correction adopt Marini-Murray model. The time relationship for the signals of differenced ranges can be expressed as

$$
\left\{\begin{array}{c}
R_{i 0}\left(t_{0}\right)=R_{0}\left(t_{0}\right)+I_{0}^{\mathrm{e}}+\tau_{\mathrm{s}}+R_{i}\left(t_{0}\right)+I_{i 0}^{\mathrm{r}} \\
+\Delta T_{i}+\Delta \tau_{\text {sag }}^{0-\mathrm{u}}+\Delta \tau_{\text {sag }}^{i-\mathrm{d}}, \\
R_{00}\left(t_{0}\right)=R_{0}\left(t_{0}\right)+I_{0}^{\mathrm{e}}+\tau_{\mathrm{s}}+R_{0}\left(t_{0}\right)+I_{00}^{\mathrm{r}},
\end{array}\right.
$$

where 0 is master station Lintong, while $i$ is slave station in order as Shanghai, Changchun, Kunming, and Urumqi; $R_{i 0}\left(t_{0}\right)$ is the observation value at the slave station $i$, received the signal from master station without the impact of the ionosphere and troposphere; $R_{00}\left(t_{0}\right)$ is the observation value at the master station, received the signal from master station without the impact of the ionosphere and troposphere; $t_{0}$ is the moment that the signal is received from master station by the satellite; $R_{0}\left(t_{0}\right)$ is the distance (with the speed of light as its unit) between the antenna phase centre of master station and the satellite antenna phase centre at the moment the signal is received from master station by the satellite; $R_{i}\left(t_{0}\right)$ is the distance (with the speed of light as its unit) between the antenna phase centre of slave station $i$ and the satellite antenna phase centre at the moment the signal is received from master station by the satellite; $I_{0}^{\mathrm{e}}$ is the instrument delay of emitting signals for master station; $I_{i 0}^{\mathrm{r}}$ is the receiver delay at slave station $i$ that receive signals from master station; $I_{00}^{\mathrm{r}}$ is the receiver delay at master station that receive signals from master station; $\Delta T_{i}$ is the clock offset at slave station $i$ with respect to the master station; $\tau_{\mathrm{s}}$ is the satellite transponder time delay; $\Delta \tau_{\text {sag }}^{0 \text { u }}$ is the uplink Sagnac correction for master station; $\Delta \tau_{\text {sag }}^{i-\text { d }}$ is the downlink Sagnac correction for slave station $i$. 
Considering eqs. (1) and (2), we have

$$
\begin{aligned}
R_{i 0}\left(t_{0}\right)-R_{00}\left(t_{0}\right)= & {\left[R_{i}\left(t_{0}\right)-R_{0}\left(t_{0}\right)\right]+\left(I_{i 0}^{\mathrm{r}}-I_{00}^{\mathrm{r}}\right) } \\
& +\Delta T_{i}+\Delta \tau_{\mathrm{sag}}^{0-\mathrm{u}}+\Delta \tau_{\text {sag }}^{i-\mathrm{d}} .
\end{aligned}
$$

$R_{i 0}\left(t_{0}\right)-R_{00}\left(t_{0}\right)$ is the differenced ranges of observation values at master station and slave stations. $R_{i}\left(t_{0}\right)-R_{0}\left(t_{0}\right)$ is the difference of distances between master station to satellite and slave station $i$ to satellite at the moment that the signal is received from master station by the satellite; the difference of coordinate vector of two stations is the vector of baseline. $\left(I_{i 0}^{\mathrm{r}}-I_{00}^{\mathrm{r}}\right)$ is the difference of receiver time delay at master station and slave station $i$ received signals from master station. $\Delta \tau_{\text {sag }}^{0 \text {-u }}$ and $\Delta \tau_{\text {sag }}^{i \text {-d }}$ are Sagnac correction for uplink of master station and downlink of slave station $i$ which can be easily computed according to theoretical formula [9-11]. $\Delta T_{i}$ is the clock offset at slave station $i$ with respect to the master station, and it can be obtained from TWSTFT. Corrected the impact of the ionosphere [12] and troposphere, the computational equation is

$$
\left\{\begin{aligned}
R_{i 0}\left(t_{0}\right)= & R_{0}\left(t_{0}\right)+I_{0}^{\mathrm{e}}+\tau_{\mathrm{s}}+R_{i}\left(t_{0}\right)+I_{i 0}^{\mathrm{r}} \\
& +\Delta T_{i}+\Delta \tau_{\mathrm{sag}}^{0-\mathrm{u}}+\Delta \tau_{\mathrm{sag}}^{i-\mathrm{d}} \\
R_{0 i}\left(t_{i}\right)= & R_{i}\left(t_{i}\right)+I_{i}^{\mathrm{e}}+\tau_{\mathrm{s}}+R_{0}\left(t_{i}\right)+I_{0 i}^{\mathrm{r}} \\
& -\Delta T_{i}+\Delta \tau_{\mathrm{sag}}^{i-\mathrm{u}}+\Delta \tau_{\mathrm{sag}}^{0-\mathrm{d}} .
\end{aligned}\right.
$$

The differenced ranges are given by

$$
\begin{aligned}
R_{i 0}\left(t_{0}\right)-R_{0 i}\left(t_{i}\right)= & {\left[R_{0}\left(t_{0}\right)-R_{0}\left(t_{i}\right)+R_{i}\left(t_{0}\right)-R_{i}\left(t_{i}\right)\right]+2 \Delta T_{i} } \\
& +I_{0}^{\mathrm{e}}-I_{i}^{\mathrm{e}}+I_{i 0}^{\mathrm{r}}-I_{0 i}^{\mathrm{r}}+2 \Delta \tau_{\text {sag }}^{0 \text {-u }}-2 \Delta \tau_{\text {sag }}^{i-\mathrm{u}} .
\end{aligned}
$$

$\left(t_{0}-t_{i}\right)$ is not in excess of $1 \mathrm{~ms}$ for the GEO satellite; the differences between $R_{0}\left(t_{i}\right)$ and $R_{0}\left(t_{0}\right), R_{i}\left(t_{i}\right)$ and $R_{i}\left(t_{0}\right)$ are the impacts by the movement of satellite. Corrected these impacts [13], eq. (6) can be rewritten as

$$
\Delta T_{i}=\frac{1}{2}\left[R_{i 0}\left(t_{0}\right)-R_{0 i}\left(t_{0}\right)\right]-\frac{1}{2}\left(I_{0}^{\mathrm{e}}-I_{0 i}^{\mathrm{r}}\right)+\frac{1}{2}\left(I_{i}^{\mathrm{e}}-I_{i 0}^{\mathrm{r}}\right) .
$$

\section{Data analysis}

The observation system for the satellite orbit survey has been constructed by five stations in China: Lintong, Changchun, Shanghai, Kunming, Urumqi, and Lintong is the master station. The satellite orbit determination for SINOSAT-1 is implemented during the observation period of 6 and 17 June, 2005. The instrumentations time delay is determined in the duration of first 10 minutes each hour. The orbit is determined using ranging data and jointly with differenced ranges, respectively [14-17].

The principle of statistical orbital determination is implemented in the data processing, with the adopted astronomical constants, reference system, and dynamical and measurement models referred to IERS96.

The dynamical perturbation models are (1) gravitational attractions of the non-spherical Earth (Earth gravity model JGM3, truncated to the 10th degree and order); three-body gravitational attractions of the Sun and Moon; (3) relativistic perturbation; (4) gravitational attractions of oceanic tides; gravitational attractions of solid-Earth tides; (5) solar radiation pressure ( $\mathrm{Cr}$ adjusted); (6) earth radiation pressure; (7) earth's rotation deformation perturbation; (8) empirical radial-transverse-normal accelerations.

The measurement models are (1) Marini-Murray refraction model; (2) the offset correction about the center of mass; (3) solid earth tides displacement; (4) permanent deformation; (5) ocean loading site displacement; (6) rotation deformation due to polar motion.

The reference systems are (1) the mean equator $(x-y$ plane) and mean spring equinox (the direction of the $x$-axis) at J2000.0; (2) ITRF2000 for the coordinates of the stations and their velocities of motion; (3) the precession model for IAU1976; (4) the 1980 nutation model and IERS nutation correction; (5) the planetary ephemeris DE403/LE403.

The dynamic method $[16,17]$ is used for precise orbit determination with a-day arc segment observation data for mode "receiving own station disseminated signals mode", and estimated parameters are 6 orbital elements, 6 solar radiation pressure parameter, 6 constant accelerations in the transverse direction, 12 transponder delay parameter. The estimated bias of each station assuming that the sum of all ranging biases is zero are proposed [3].

The precise orbit determination with a-day arc segment observation data jointed ranging and differenced ranges is also implemented, and the estimated parameters are 6 orbital elements, 6 solar radiation pressure parameters, 6 constant accelerations in the transverse direction, 12 transponder delay parameters. The estimated bias of each station assuming that the sum of all ranging biases is zero are also proposed.

Table 1 shows the residuals (RMS) of POD with a 1-day arc segment observation data under for using ranging data only and jointly with differenced ranges, respectively.

Table 2 shows the orbital overlapping results of the two modes in detail. The overlapping accuracy of combined mode in the normal direction is better than that using ranging data only. It means that the combined mode has the strategy in the normal direction of satellite orbit.

The determination of the orbit and its prediction with a combination of ranging and differenced ranges are researched. In order to show the improvement of orbit determination with differenced ranging, we choose three different observation periods at $02: 10,08: 10,12: 10$ on June 6 , 2005 and at 00:10, 08:10, 12:10 on June 17, 2005 with two different observation arcs for $5 \mathrm{~min}$ and $30 \mathrm{~min}$ to test orbit determination with differenced ranges strategy.

The influences of systematic errors are considered. The orbit determination using the data of two modes is made, and the biases of ranging and differenced ranges are solved. The short-arc orbit determination and prediction are researched in order to test the rapid orbit recovery after satellite maneuvers. For the short-arc orbit determination with a 
Table 1 Residuals of one day arc observation (unit: $\mathrm{m}$ )

\begin{tabular}{|c|c|c|c|c|c|c|c|}
\hline \multirow{3}{*}{ Date } & \multirow{2}{*}{\multicolumn{2}{|c|}{ Ranging data only }} & \multicolumn{5}{|c|}{ Ranging data combined with differenced ranges } \\
\hline & & & \multicolumn{2}{|l|}{ ranging data } & \multicolumn{2}{|l|}{ differenced ranges } & \multirow{2}{*}{$\begin{array}{c}\text { combined } \\
\text { RMS }\end{array}$} \\
\hline & ranging data number & RMS & ranging data number & RMS & differenced ranges number & RMS & \\
\hline Period of June 6 at 2:00 to June 7 at 2:00 & 358982 & 0.062 & 358982 & 0.060 & 69355 & 0.054 & 0.059 \\
\hline Period of June 6 at $14: 00$ to June 7 at 14:00 & 359240 & 0.062 & 359240 & 0.062 & 69614 & 0.067 & 0.063 \\
\hline Period of June 17 at $0: 00$ to June 18 at $0: 00$ & 354835 & 0.065 & 354835 & 0.061 & 280764 & 0.094 & 0.077 \\
\hline
\end{tabular}

Table 2 Statistics of overlapped orbit differences in RTN (unit: m) ${ }^{\text {a) }}$

\begin{tabular}{lllll}
\hline \multicolumn{1}{c}{ Mode } & Delta $R$ & Delta $T$ & Delta $N$ & Delta pos. \\
\hline Ranging data only & 0.623 & 0.770 & 1.228 & 1.578 \\
Combined POD & 0.815 & 0.721 & 0.948 & 1.443 \\
\hline
\end{tabular}

a) Duration: June 6 at 02:00 - June 7 at 02:00 and June 6 at 14:00 - June 7 at 14:00.

period of 5 min observations, only 6 orbital elements are estimated, while with a period of $30 \mathrm{~min}$ observations 6 orbital elements plus a solar radiation pressure parameter are estimated.

The orbit prediction using ranging combined with differenced ranges is made with observation arc of 5 min lasts $4 \mathrm{~h}$ and observation arc of 30 min lasts $12 \mathrm{~h}$, respectively.
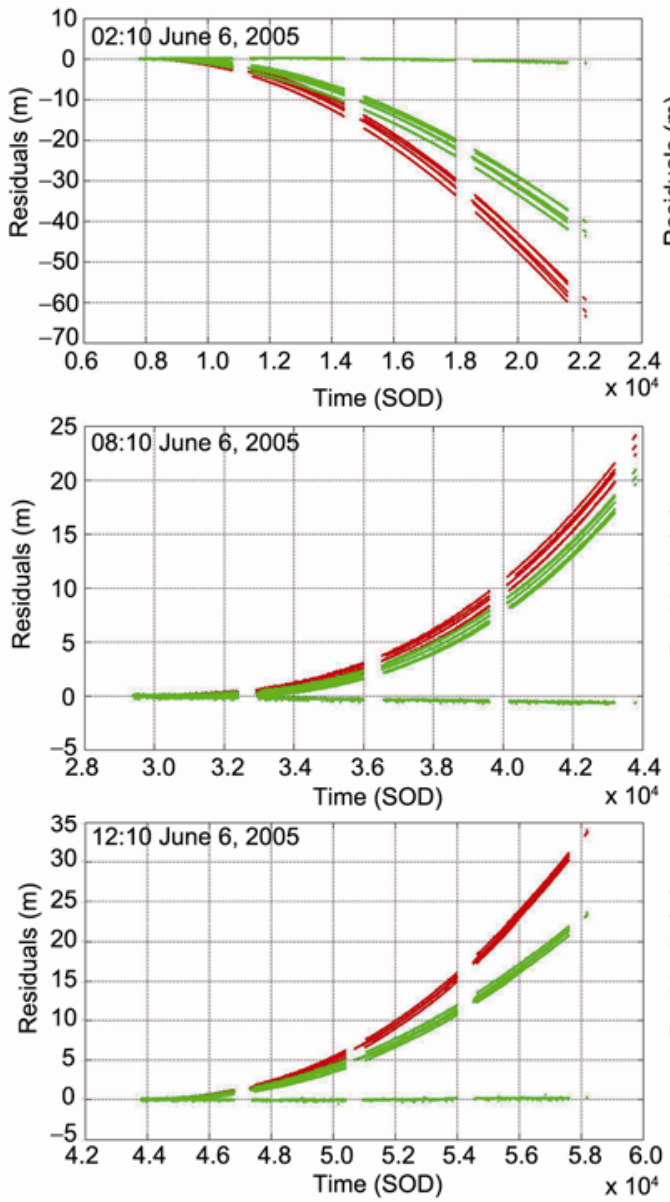

(a)
Figures 2 and 3 show the comparison of residuals (O-C).

Obviously, differenced ranges are much better than others to improve short-arc POD accuracy for the rapid satellites orbit recovery. The red lines show the residuals of orbit prediction using ranging data only; the green lines show the residuals of orbit prediction using differenced ranges and ranging data on June 6 and 17, 2005.
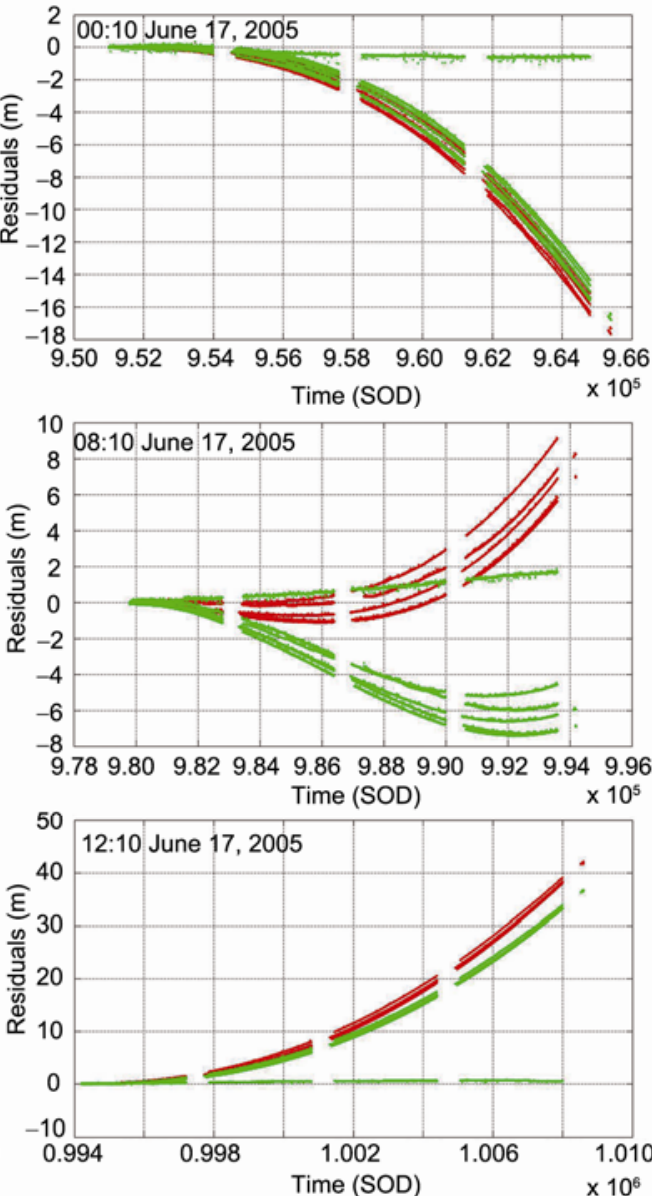

(b)

Figure 2 Comparison of residuals (O-C) with observation arc of 5 min lasts $4 \mathrm{~h}$ (second of day, SOD). (a) Residuals of orbit precision on June 6; (b) residuals of orbit precision on June 17. 

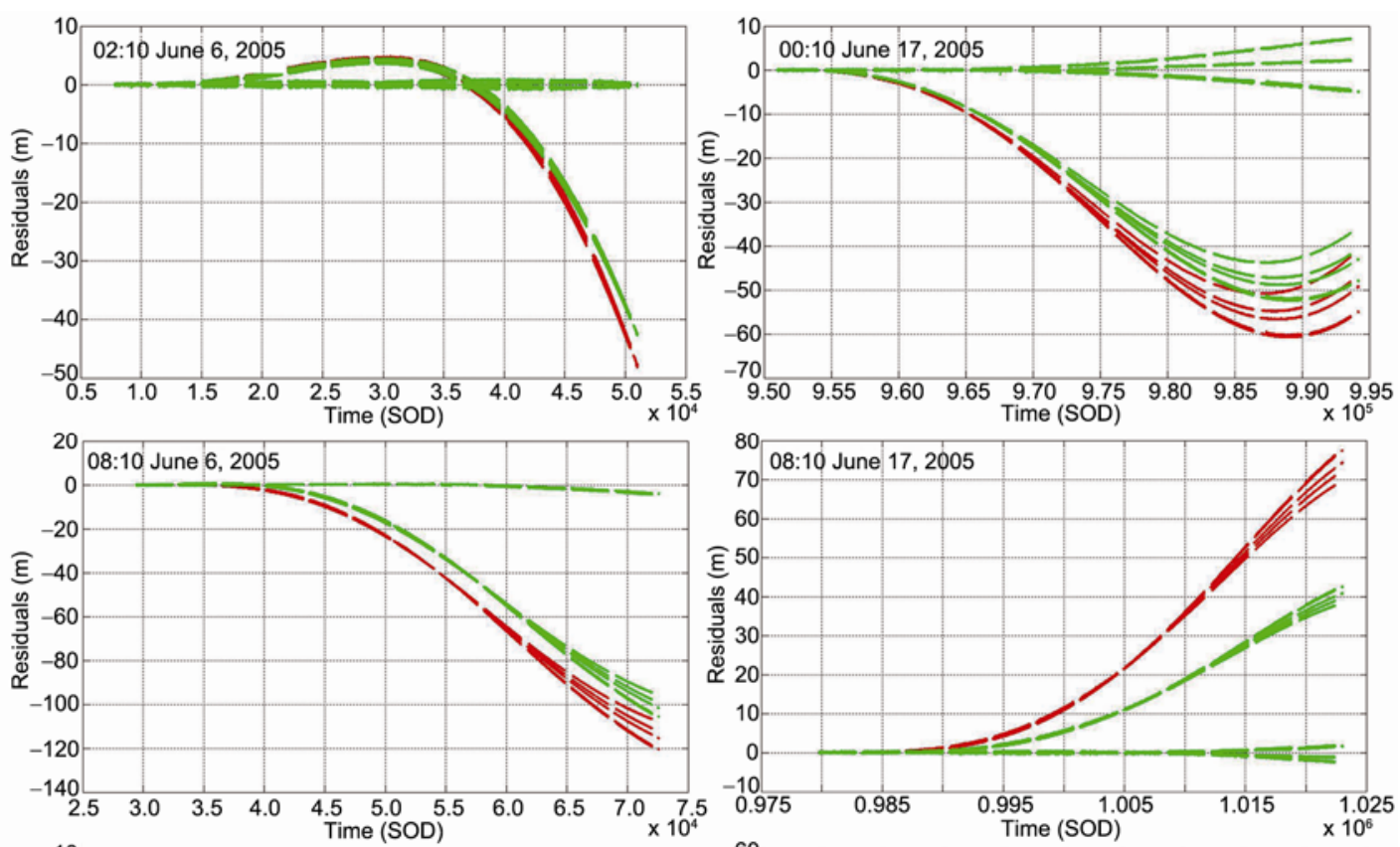

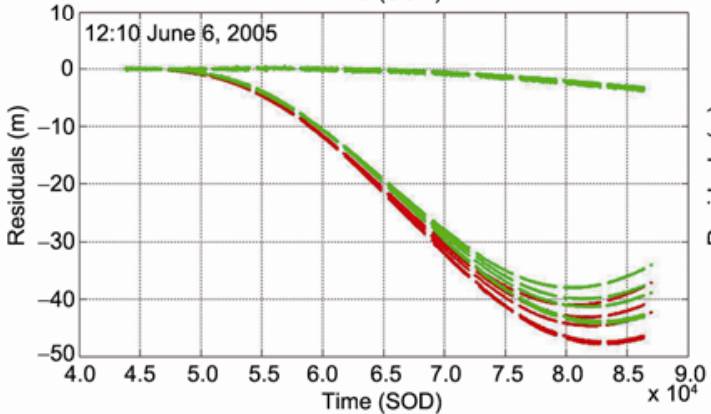

(a)

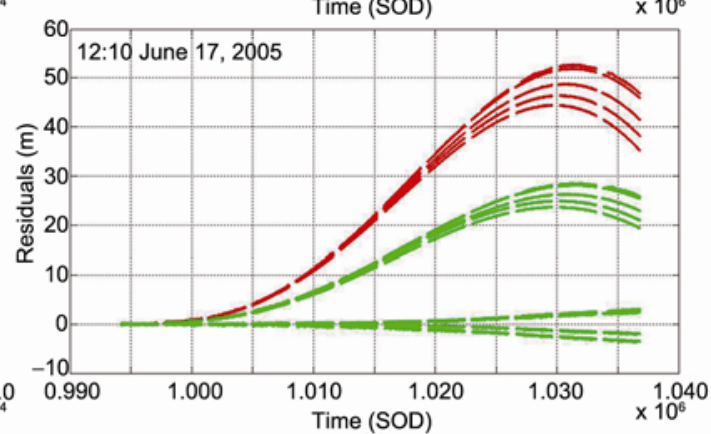

(b)

Figure 3 Comparison of residuals (O-C) with observation arc of 30 min lasts $12 \mathrm{~h}$ (second of day, SOD). (a) Residuals of orbit precision on June 6; (b) residuals of orbit precision on June 17.

Table 3 Orbital differences with various modes (unit: $m)^{\text {a) }}$

\begin{tabular}{|c|c|c|c|c|c|}
\hline The start observation time & Strategy & Delta $R$ & Delta $T$ & Delta $N$ & Delta pos. \\
\hline \multirow{2}{*}{$02: 10$} & ranging data only & 34.250 & 8.859 & 65.221 & 74.198 \\
\hline & combined & 25.623 & 8.167 & 66.713 & 71.930 \\
\hline \multirow{2}{*}{$08: 10$} & ranging data only & 9.121 & 14.184 & 1.181 & 16.904 \\
\hline & combined & 8.302 & 12.330 & 5.857 & 15.977 \\
\hline \multirow{2}{*}{$12: 10$} & ranging data only & 15.753 & 3.799 & 14.393 & 21.674 \\
\hline & combined & 11.853 & 3.605 & 17.029 & 21.059 \\
\hline
\end{tabular}

a) Date: June 6; observation arc: $5 \mathrm{~min}$; orbit predicted: $4 \mathrm{~h}$.

Table 4 Orbital differences with various modes (unit: $m$ ) ${ }^{\text {a) }}$

\begin{tabular}{|c|c|c|c|c|c|}
\hline The start observation time & Strategy & Delta $R$ & Delta $T$ & Delta $N$ & Delta pos. \\
\hline \multirow{2}{*}{$00: 10$} & ranging data only & 5.234 & 1.941 & 23.127 & 23.792 \\
\hline & combined & 4.957 & 1.460 & 21.736 & 22.342 \\
\hline \multirow{2}{*}{ 08:10 } & ranging data only & 2.862 & 11.850 & 41.828 & 43.568 \\
\hline & combined & 7.587 & 6.292 & 32.870 & 34.316 \\
\hline \multirow{2}{*}{$12: 10$} & ranging data only & 17.068 & 9.813 & 12.515 & 23.329 \\
\hline & combined & 14.899 & 7.199 & 9.299 & 18.981 \\
\hline
\end{tabular}

a) Date: June 17; observation arc: $5 \mathrm{~min}$; orbit predicted: $4 \mathrm{~h}$. 
Table 5 Orbital differences with various modes (unit: $m)^{\text {a) }}$

\begin{tabular}{|c|c|c|c|c|c|}
\hline The start observation time & Strategy & Delta $R$ & Delta $T$ & Delta $N$ & Delta pos. \\
\hline \multirow{2}{*}{ 02:10 } & ranging data only & 13.487 & 9.552 & 14.685 & 22.109 \\
\hline & combined & 11.978 & 7.791 & 14.452 & 20.323 \\
\hline \multirow{2}{*}{$08: 10$} & ranging data only & 55.345 & 54.188 & 6.894 & 77.762 \\
\hline & combined & 53.011 & 50.121 & 8.502 & 73.447 \\
\hline \multirow{2}{*}{$12: 10$} & ranging data only & 28.066 & 46.488 & 7.016 & 54.754 \\
\hline & combined & 27.313 & 45.541 & 6.237 & 53.468 \\
\hline
\end{tabular}

a) Date: June 6; observation arc: $30 \mathrm{~min}$; orbit predicted: $12 \mathrm{~h}$.

Table 6 Orbital differences with various modes (unit: $m)^{\text {a) }}$

\begin{tabular}{|c|c|c|c|c|c|}
\hline The start observation time & Strategy & Delta $R$ & Delta $T$ & Delta $N$ & Delta pos. \\
\hline \multirow{2}{*}{$00: 10$} & ranging data only & 36.596 & 71.044 & 13.085 & 80.980 \\
\hline & combined & 31.615 & 61.328 & 11.810 & 70.001 \\
\hline \multirow{2}{*}{ 08:10 } & ranging data only & 33.381 & 33.027 & 7.243 & 47.513 \\
\hline & combined & 18.037 & 17.523 & 5.823 & 25.813 \\
\hline \multirow{2}{*}{$12: 10$} & ranging data only & 30.048 & 60.875 & 9.856 & 68.599 \\
\hline & combined & 16.942 & 35.642 & 6.341 & 39.970 \\
\hline
\end{tabular}

a) Date: June 17; observation arc: $30 \mathrm{~min}$; orbit predicted: $12 \mathrm{~h}$.

Figure 2 shows the residuals of orbit with observation arc of $5 \mathrm{~min}$ and the prediction orbit lasted $4 \mathrm{~h}$. Figure 3 shows the residuals of orbit with observation arc of $30 \mathrm{~min}$ and the prediction orbit lasted $12 \mathrm{~h}$. They show that differenced ranges are available to improve POD accuracy in combined orbit determination for the rapid orbit recovery of satellite. Tables 3-6 show the results in detail. The data in these tables illustrate the effectiveness of differenced ranges. The orbital difference with the combined POD is less than the orbital difference only with ranging data under difference observation time.

\section{Conclusions}

The mode of differenced ranges between master station and slave stations is a new observation mode for the determination of satellite orbit by transfer. A comparison of accuracy of orbit determination and prediction was made for the various modes. This is the first time the mode of differenced ranges has been used in orbit determination. It shows that the orbit determination with differenced ranges can improve the orbital accuracy greatly. The accuracy of orbit determination is limited by the systematic error of instrument. It can be improved by modifying the design of observation equipments. Obviously, the method presented in this paper is valuable for application in the field of precision orbit determination, especially for the rapid satellites orbit recovery in orbit prediction to improve short-arc POD accuracy.

1 Ai G X, Shi H L, Wu H T. Transponder satellite communications navigation and positioning system (in Chinese). PRC Patent, 200410046064, 2004
2 Ai G X, Shi H L, Wu H T, et al. A positioning system based on communication satellites and the Chinese area positioning system (CAPS). Chin J Astron Astrophys, 2008, 8: 611-630

3 Li Z G, Yang X H, Ai G X, et al. A new method for determination of satellite orbits by transfer. Sci China Ser G Phys Mech Astron, 2009, 52: 384-392

4 Guo R, Hu X G, Tang B, et al. Precise orbit determination for geostationary satellites with multiple tracking techniques. Chin Sci Bull, 2010, 55: 687-692

5 Yan J G, Ping J S, Li F, et al. Chang'E-1 precision orbit determination and lunar gravity field solution. Adv Space Res, 2010, 46: 50-57

6 Wang H, Dong G L, Hu X G, et al. Joint orbit determination for SMART-1 with USB-VLBI (in Chinese). Sci Survey Map, 2008, 33: 40-41

7 Huang Y, Hu X G, Zhang X Z, et al. Improvement of orbit determination for geostationary satellites with VLBI tracking. Chin Sci Bull, 2011, 56: 2765-2772

8 Li Z G, Cheng Z Y, Feng C G, et al. Research of ionosphere forecast model (in Chinese). Chin J Geophys, 2007, 50: 327-337

$9 \mathrm{Li} \mathrm{Z} \mathrm{G,} \mathrm{Li} \mathrm{H} \mathrm{X,} \mathrm{Zhang} \mathrm{H.} \mathrm{A} \mathrm{method} \mathrm{for} \mathrm{processing} \mathrm{multi-station} \mathrm{data}$ on two-way satellite time transfer with two-channel modems (in Chinese). Pub Shaanxi Astron Observ, 2002, 25: 81-89

10 Imae M, Hosokawa M, Imamura K. Two-way satellite time and frequency transfer networks in Pacific Rim region. IEEE Trans Instrum Meas, 2001, 50: 559-562

11 Li Z G, Li H X, Zhang H. The reduction of two-way satellite time comparison. Chin Astron Astrophys, 2003, 27: 226-235

12 Merck J P, Achkar J. Typical combined uncertainty evaluation on the $\mathrm{Ku}$ band TWSTFT link. In: Proceedings of the 19th European Frequency and Time forum (EFTF), 2005

13 Li Z G, Qiao R C, Feng C G. Two way satellite time transfer (TWSTT) and satellite ranging (in Chinese). J Spacecraft TT\&C Tech, 2006, 25: 1-6

14 Li J S. Precise Orbit Determination of Satellites. Beijing: People's Liberation Army Publishing House, 1995. 3-13

15 Escobal P R. Methods of Orbit Determination. USA: Krieger Pulishing Company, 1976

16 Montenbruck O, Gill E. Satellite Orbits. New York: Springer, 2000

17 France B, Cunningham J P, Swift E R, et al. Improvement of the NIMA precise orbit and clock estimates. In: Proceedings of ION GPS-98, Nashville, Tennessee, 1998. 1587-1596

Open Access This article is distributed under the terms of the Creative Commons Attribution License which permits any use, distribution, and reproduction in any medium, provided the original author(s) and source are credited. 